\title{
CUSTOS OPERACIONAIS DE CAPTURA DA FROTA CAMAROEIRA DO LITORAL NORTE DO ESTADO DE SÃO PAULO: ANÁLISE COMPARADA ENTRE VALORES DE MERCADO E VALORES DE COOPERADOS
}

\author{
AZEVEDO, V.G. ${ }^{1,2}$; BARBOSA, M. N. ${ }^{3}$; ABDALLAH, P.R. ${ }^{3}$ \& ROSSI-WONGTSCHOWSKI, C.L.D.B. ${ }^{2}$ \\ 1 - Instituto de Pesca - SP \\ 2 - Instituto Oceanográfico - USP \\ 3 - UPEC - Universidade Federal do Rio Grande \\ *Corresponding author: vazevedo@pesca.sp.gov.br
}

\begin{abstract}
Azevedo, V.G.; Barbosa, M. N.; Abdallah, P.R. \& Rossi-Wongtschowski, C.L.D.B. (2014) Custos operacionais de captura da frota camaroeira do litoral norte do Estado de São Paulo: análise comparada entre valores de mercado e valores de cooperados. Braz. J. Aquat. Sci. Technol. 18(1): 71-79. elSSN 1983-9057. DOI: 10.14210/bjast.v18n1. p71-79 The seabob shrimp (Xiphopenaeus kroyeri) fishery is very important at the northern coast of São Paulo State as a source of incomes and jobs. In addition, this activity also provides stable trade for this product. The present study evaluated the Total Operating Cost (TOC) for three groups of vessels engaged in this fishery (G1, G2 and G3) depending on their physical characteristics (vessel length, gross tonnage and engine power), with G1 including the largest vessels with the most powerful engines, and, in contrast, G3 with the smallest gross tonnage vessels and $\mathrm{G} 2$, an intermediate group between these two. The results indicate that fuel (diesel) represents the highest source of costs for all groups. Under the schemes of cooperative or market value a small difference was found in the profits among the three groups of boats not showing direct economic benefits that would encourage permanent cooperative engagement. However, the adhesion of fisher to cooperatives occurs due to strong ties between them and can provide security as regarding marketing and preservation of the catches.
\end{abstract}

Key-words: Xiphopenaeus kroyeri; operating cost, cooperativism, artisanal fishery.

\section{INTRODUÇÃO}

Com exceção da pesca de subsistência, praticamente todas as pescarias são atividades comerciais, onde mesmo na modalidade de menor escala os pescadores vendem o excedente de seu produto para atender às suas necessidades domésticas (Berkes et al., 2001). Neste sentido, a análise econômica das pescarias se torna imprescindível, visto que a economia pode ajudar a esclarecer como os agentes econômicos respondem às mudanças das regras, quanto às suas escolhas sobre os insumos, tecnologias de produção e investimentos (Dupont \& Gordon, 2007), além do comportamento dos pescadores no tempo e no espaço (Anderson \& Seijo, 2010). Pode servir também como um guia para verificar se as regras que regem pescarias são apropriadas (Hanneson, 2002).

No Brasil, estudos sobre a avaliação dos estoques pesqueiros nem sempre têm levado em conta a caracterização socioeconômica e organizacional da atividade, apesar da sua importância e influência no manejo desses estoques (Abdallah \& Castello, 2003; Ribemboim, 2010). Esse é o caso do camarão-sete-barbas (Souza et al., 2009), sendo que poucos autores como Finco et al. (2003), Dapper (2009), Espírito Santo (2012) e Kalikoski \& Vasconcelos (2012), desenvolveram análises de custo de captura de diferentes espécies marinhas, entre outras caracterizações de pescarias costeiras.
A atividade pesqueira no litoral norte do Estado de São Paulo é muito importante para a região e em termos econômicos merece destaque, ao lado do turismo e da construção civil (SEMA, 2005). Dentre as modalidades de pesca ali existentes, destaca-se a do camarão-sete-barbas, Xiphopenaeus kroyeri (Heller, 1862), devido sua relevância econômica e social como fonte de empregos diretos e indiretos e de renda (Graça Lopes et al., 2007). Entre os anos 2008 e 2010, o volume capturado de camarão-sete-barbas foi de 8235 toneladas, o que correspondeu a $9,8 \%$ do total de pescado desembarcado no Estado, sendo o litoral norte responsável por $14 \%$ deste total, ou seja, 1.150 toneladas (Instituto de Pesca, 2012). De acordo com informações provenientes do Programa de Monitoramento da Atividade Pesqueira, desenvolvido pelo Instituto de Pesca, o camarão-sete-barbas ocupou em 2008 a segunda colocação entre os produtos marinhos desembarcados no Estado de São Paulo e a terceira em 2009 e 2010.

No presente trabalho foram avaliados os custos das viagens realizadas pelos três grupos de embarcações que capturam o camarão-sete-barbas no litoral norte do Estado de São Paulo, distintas por suas características físicas (comprimento total, potência do motor e arqueação bruta), segundo Azevedo et al. (2014).

Foram analisados o Custo Operacional Total (COT) e a rentabilidade das embarcações que capturam o recurso e que estão associadas à Cooperativa 
de Pesca de São Sebastião - COOPERPESCASS, no município de São Sebastião (SP). A rentabilidade dessas embarcações foi analisada quando sujeitas ao regime de valor de cooperativa e, quando sujeitas ao regime de valor de mercado.

Em caso de não existir uma diferença real entre a rentabilidade de uma embarcação cooperada e uma não cooperada, questiona-se, então, qual a vantagem em se tornar um cooperado. A fim de se responder a esta pergunta serão utilizados arcabouços teóricos que enfocam o comportamento do pescador, como a teoria dos laços. Esta teoria mostra que as organizações sociais são compostas por diversos tipos de laços, como os de amizade e os de trabalho. A intensidade desses laços é variável, podendo eles ser fortes e fracos, assim como seu conteúdo, que pode estar relacionado a recursos, informações e afeto (Granovetter, 1973; Granovetter, 2005; Lopes \& Baldi, 2005). Segundo estes últimos autores, a confiança é um dos resultados da existência de laços sociais e desempenha papel chave na formação de arranjos cooperativos.

Este trabalho tem por objetivo o maior conhecimento econômico do funcionamento desta pescaria, visando contribuir para o estabelecimento e adequação de políticas públicas voltadas ao ordenamento pesqueiro.

\section{MATERIAIS E MÉTODOS}

Tendo como base a teoria econômica para análise de custos, utilizou-se o método de coleta, organização e análise dos dados para estudo dos custos operacionais propostos, sendo utilizados dados secundários a respeito das características físicas e capturas da frota de arrasto que atua no litoral norte de São Paulo, provenientes do Programa de Monitoramento da Atividade Pesqueira, desenvolvido pelo Instituto de Pesca/APTA/SAA, que opera de forma censitária, da Cooperativa de Pesca de São Sebastião - COOPERPESCASS, os que dizem respeito às capturas, custos e ganhos das embarcações cooperadas, além do preço de primeira comercialização dos pescados e, dados coletados no mercado, como o preço do óleo diesel, gelo e outros itens necessários às operações de pesca, todos relativos a valores em reais, de 2009.

Foram considerados os resultados obtidos por Azevedo et al. (2014) que mostram, na pesca do camarão sete-barbas do litoral norte de São Paulo, a operação de três grupos de embarcações denominadas G1, G2 e G3, distintas em suas características físicas (comprimento total (CT) em metros, potência do motor (PM) em "Horse Power" e arqueação bruta $(A B)$ em toneladas). Estes autores identificaram que a potência do motor e o comprimento separam o G1 (embarcações maiores e com maior motorização) do G2 e do G3 enquanto que a arqueação bruta distingue as embarcações do grupo G3 (embarcações menores e com menos motorização) das demais, conforme apresentado detalhadamente na tabela 1 .

Para as análises sobre os custos de viagem e receitas das capturas, foram consideradas embarcações de cada um dos grupos mencionados, que estavam associadas à Cooperativa de Pesca de São Sebastião - COOPERPESCASS, sendo que seis pertenciam ao G1, cinco ao G2 e quatro ao G3.

Devido ao número reduzido de embarcações que realizaram descargas do camarão-sete-barbas na COOPERPESCASS durante o período de 2008 a 2010, foram analisados apenas os dados de 2009, ano em que ocorreram descargas dos três grupos de embarcações em todos os meses de atividade, sendo selecionados os registros de descargas de duas embarcações por grupo.

Nos registros de descargas são encontradas três categorias de camarão-sete-barbas: "camarão-sete-barbas", "camarão-sete-barbas escolhido" e "camarão-sete-barbas especial", que tem diferentes valores de venda. Para as analises deste estudo estas categorias foram agrupadas, sendo utilizado o preço médio de revenda. Foi também analisada a categoria "espécies diversas", geralmente compostas por peixes, moluscos e crustáceos, que são aproveitados e comercializados pelo pescador, além do camarão-sete-barbas.

Para a análise do Custo Operacional Total (COT) (Matsunaga, 1976; Martin et. al, 1994) foram considerados os custos mensais de operação (de duas embarcações por grupo) para as quais havia dados sobre os custos médios relativos aos itens óleo combustível (diesel), óleo lubrificante, rancho (alimentação dos tripulantes), compra e manutenção de petrecho de pesca, gelo, sulfito (Bissulfito de sódio $-\mathrm{NaHSO}_{3}$ ) e manutenção da embarcação (serviços de mecânica, elétrica, carpintaria, etc.). O Bissulfito de sódio - NaHSO3, popularmente chamado de "sulfito" é utili-

Tabela1 - Características dos grupos de embarcações (G1, G2 e G3) que operam na pesca do camarão-sete-barbas no litoral norte de São Paulo: Comprimento Total em metros, potência do motor em "Horse Power", Arqueação Bruta em toneladas e Número de Embarcações atuantes em cada grupo (N). Fonte: Azevedo (2013).

\begin{tabular}{clrrr}
\hline \hline & & \multicolumn{1}{c}{ G1 } & G2 & G3 \\
\hline \multirow{2}{*}{ Arqueação Bruta } & Mínimo & 0,8 & 1,8 & 0,2 \\
(ton) & Médio & 5,6 & 4,1 & 1,6 \\
& Máximo & 19,8 & 7,8 & 3,5 \\
Comprimento Total & Mínimo & 7,0 & 5,5 & 4,6 \\
(m) & Médio & 9,4 & 8,0 & 7,7 \\
& Máximo & 13,5 & 10,5 & 9,8 \\
Potência do Motor & Mínimo & 33,0 & 9,0 & 6,0 \\
(HP) & Médio & 64,0 & 19,0 & 16,8 \\
$\mathrm{~N}$ & Máximo & 157,0 & 33,0 & 26,0 \\
& & 86 & 72 & 82 \\
\hline \hline
\end{tabular}


zado como um inibidor da melanose, a qual provoca o aparecimento de manchas negras no camarão e, leva à diminuição de sua qualidade e validade (Meneses \& Ogawa, 1977; Mendes, 2005; Furlan, 2011). Não foram considerados os dados referentes ao período de defeso, de março a maio (IBAMA, 2008). Os custos relativos à mão de obra também não foram incluídos na análise, uma vez que, segundo a COOPERPESCASS, a remuneração dos pescadores foi proveniente da receita obtida com a venda do pescado e, distribuída através de um sistema de partes e, não na forma de um salário propriamente dito. A depreciação das embarcações também não entrou na análise pela falta de dados disponíveis. Uma vez que não foi computada na análise a totalidade dos custos das operações de pesca, os retornos monetários das operações de pesca serão aqui chamados de rendimentos.

Levando em conta que na COOPERPESCASS os valores de alguns bens (diesel, gelo, óleo lubrificante e sulfito) cobrados aos associados são diferentes dos encontrados no mercado, foram analisados dois cenários para o cálculo do COT: Valor de Cooperativa e Valor de Mercado. Para a análise do COT Valor de Mercado, as informações sobre os preços dos itens analisados foram obtidas junto a armadores e empresários de pesca (cinco entrevistas telefônicas), calculando-se um valor médio para a região, também para 2009. O preço médio do óleo diesel para a região Sudeste, para este período, foi obtido em consulta ao site da Agência Nacional do Petróleo, Gás Natural e Biocombustíveis - ANP (ANP, 2013).

Informações das capturas realizadas pelos grupos de embarcações são provenientes da COOPERPESCASS. O COT Médio de cada grupo foi calculado através da média das despesas realizadas por duas embarcações em 2009. A receita bruta média de cada grupo foi calculada através dos rendimentos obtidos pela venda dos produtos capturados por duas embarcações. Maior detalhamento sobre os cálculos realizados encontram-se em Azevedo (2013).

\section{RESULTADOS}

Será apresentado, numa primeira parte o COT Valor de Cooperativa, que se refere aos custos operacionais de embarcações cooperadas que atuam na captura do camarão-sete-barbas, no litoral norte de São Paulo. Em seguida o COT Valor de Mercado para estas mesmas embarcações, porém utilizando os custos de mercado. Posteriormente será feita a análise comparativa dos dois COTs (Valor de Cooperativa e Valor de Mercado). Em seguida serão avaliadas as Capturas, COT médio e Receita bruta média pelos grupos de embarcações. Por fim será apresentada a análise comparativa do COT médio, nos diferentes grupos de embarcações, a partir dos cenários analisados.

\section{Custos das operações de pesca das embarcações - Valores de Cooperativa.}

O óleo combustível, rancho e gelo foram os itens de maior custo operacional para os três grupos considerados na análise, sendo que o G1 apresentou o maior valor de COT em 2009 (Tabela 2).

O óleo combustível (diesel) foi responsável pela maior parte dos custos, representando mais de $60 \%$ do COT para todos os grupos de embarcações, sendo seu valor maior para as embarcações do G1, seguido do G3 e por fim do G2(Tabela 2).

Com relação ao óleo lubrificante, o grupo G1 apresentou o maior custo. O gelo foi a segunda maior fonte de custo das embarcações do grupo G1 e a quarta para $\mathrm{G} 2$ e G3, sendo que o montante com gelo pelas embarcações do $\mathrm{G} 1$ foi mais do que o dobro dos demais grupos.

\section{Custos das operações de pesca das embarcações - Valores de Mercado.}

O G1 apresentou o maior valor de COT (Tabela 3). O óleo combustível (diesel) foi responsável pela maior parte dos custos, representando mais de $62 \%$ do custo total em todos os grupos de embarcações. Em segundo lugar ficou o rancho para as embarcações dos grupos G2 e G3 e o gelo para embarcações do G1. Constatou-se que, em ambos os cenários (Tabelas $2 \mathrm{e}$ 3 ), a ordem de participação percentual dos itens componentes dos custos operacionais totais se manteve para os grupos G1 e G3, ocorrendo pouca alteração para o grupo G2.

\section{Comparação entre Valor de Cooperativa e Valor de Mercado}

Os custos operacionais dos itens analisados relativos ao Valor Médio de Cooperativa" e ao "Valor Médio de Mercado" encontram-se na Tabela 4. O gelo apresentou a maior variação entre os custos seguido dos itens sulfito e óleo lubrificante. No ano de 2009, apenas o custo com diesel das embarcações cooperadas ficou abaixo do custo deste mesmo item, analisado em Valor de Mercado, porém com uma variação de apenas $1 \%$.

\section{Capturas, COT médio e Receita bruta média pelos grupos de embarcações associadas à COOPERPESCASS.}

Constatou-se que as capturas de camarão e de "espécies diversas", assim como a captura total, foram semelhantes entre as embarcações dos grupos G1 e G3, enquanto que as embarcações do G2 registraram o menor valor de captura total e a maior 
Tabela 2 - Custo anual das operações de pesca de duas embarcações nos diferentes grupos atuantes na pesca do camarão-sete-barbas no litoral norte de São Paulo, sob o regime de Valor de Cooperativa no ano 2009.

\begin{tabular}{|c|c|c|c|c|c|c|c|c|c|}
\hline & \multicolumn{3}{|c|}{ G1 } & \multicolumn{3}{|c|}{ G2 } & \multicolumn{3}{|c|}{ G3 } \\
\hline Descrição & & Valor & $\%$ & & Valor & $\%$ & & Valor & $\%$ \\
\hline Óleo Combustível & $\mathrm{R} \$$ & $37.750,50$ & $73,1 \%$ & $\mathrm{R} \$ 1$ & $4.806,60$ & $61,1 \%$ & $\mathrm{R} \$ 2$ & $20.555,81$ & $63,9 \%$ \\
\hline Óleo Lubrificante & $\mathrm{R} \$$ & $1.512,00$ & $2,9 \%$ & $\mathrm{R} \$$ & 797,00 & $3,3 \%$ & $\mathrm{R} \$$ & 835,25 & $2,5 \%$ \\
\hline Rancho & $\mathrm{R} \$$ & $3.212,31$ & $6,2 \%$ & $\mathrm{R} \$$ & $3.717,11$ & $14,5 \%$ & $\mathrm{R} \$$ & $4.059,30$ & $12,6 \%$ \\
\hline Materiais $\mathrm{p} /$ pescaria & $\mathrm{R} \$$ & $2.006,52$ & $3,9 \%$ & $\mathrm{R} \$$ & $2.260,05$ & $8,8 \%$ & $\mathrm{R} \$$ & $1.368,56$ & $5,3 \%$ \\
\hline Gelo & $\mathrm{R} \$$ & $5.022,50$ & $9,7 \%$ & $\mathrm{R} \$$ & $2.404,50$ & $9,5 \%$ & $\mathrm{R} \$$ & $2.208,50$ & $6,8 \%$ \\
\hline Sulfito & $\mathrm{R} \$$ & $1.054,35$ & $2,0 \%$ & $\mathrm{R} \$$ & 562,65 & $2,2 \%$ & $\mathrm{R} \$$ & 550,00 & $1,8 \%$ \\
\hline Manutenção (equipamentos) & $\mathrm{R} \$$ & $1.113,97$ & $2,2 \%$ & $\mathrm{R} \$$ & 143,48 & $0,6 \%$ & $\mathrm{R} \$$ & $2.301,54$ & $7,0 \%$ \\
\hline Total & $\mathrm{R} \$$ & $51.672,15$ & & $\mathrm{R} \$ 2$ & $4.691,39$ & & & $31.878,96$ & \\
\hline
\end{tabular}

Tabela 3 - Custo anual das operações de pesca de duas embarcações nos diferentes grupos atuantes na pesca do camarão-sete-barbas no litoral norte de São Paulo sob o regime de Valor de Mercado no ano 2009.

\begin{tabular}{|c|c|c|c|c|c|c|c|c|c|}
\hline & & \multicolumn{2}{|l|}{ G1 } & \multicolumn{3}{|c|}{ G2 } & \multicolumn{3}{|c|}{ G3 } \\
\hline Descrição & & Valor & $\%$ & & Valor & $\%$ & & Valor & $\%$ \\
\hline Óleo Combustível & $\mathrm{R} \$$ & $38.128,01$ & $74,9 \%$ & $\mathrm{R} \$ 1$ & $4.954,67$ & $61,6 \%$ & $\mathrm{R} \$ 2$ & $0.761,37$ & $64,8 \%$ \\
\hline Óleo Lubrificante & $\mathrm{R} \$$ & $1.326,02$ & $2,6 \%$ & $\mathrm{R} \$$ & 698,97 & $2,9 \%$ & $\mathrm{R} \$$ & 732,51 & $2,3 \%$ \\
\hline Rancho & $\mathrm{R} \$$ & $3.212,31$ & $6,3 \%$ & $\mathrm{R} \$$ & $3.717,11$ & $15,3 \%$ & $\mathrm{R} \$$ & $4.152,14$ & $13,0 \%$ \\
\hline Materiais $p /$ pescaria & $\mathrm{R} \$$ & $2.039,22$ & $4,0 \%$ & $\mathrm{R} \$$ & $2.260,05$ & $9,3 \%$ & $\mathrm{R} \$$ & $1.739,01$ & $5,4 \%$ \\
\hline Gelo & $\mathrm{R} \$$ & $4.168,68$ & $8,2 \%$ & $\mathrm{R} \$$ & $1.995,74$ & $8,2 \%$ & $\mathrm{R} \$$ & $1.833,06$ & $5,7 \%$ \\
\hline Sulfito & $\mathrm{R} \$$ & 948,17 & $1,9 \%$ & $\mathrm{R} \$$ & 500,22 & $2,1 \%$ & $\mathrm{R} \$$ & 517,97 & $1,6 \%$ \\
\hline Manutenção (equipamentos) & $\mathrm{R} \$$ & $1.113,97$ & $2,2 \%$ & $\mathrm{R} \$$ & 143,48 & $0,6 \%$ & $\mathrm{R} \$$ & $2.301,54$ & $7,2 \%$ \\
\hline Total & $\mathrm{R} \$$ & $50.936,38$ & & $\mathrm{R} \$ 2$ & $24.270,23$ & & $\mathrm{R} \$$ & $32.037,59$ & \\
\hline
\end{tabular}

de "espécies diversas" (Tabela 5). As embarcações do grupo G1 obtiveram maior rendimento médio e receita bruta média, sendo as capturas de "espécies diversas" responsáveis por estes valores.

\section{Análise Comparativa: Custo Operacional Total médio, nos diferentes grupos de embarcações, a partir dos cenários analisados}

Os resultados mostram que, apesar das embarcações dos grupos G1e G3 apresentarem rendimentos aproximados, o que se entende como um resultado econômico positivo para ambos os grupos, a participação percentual do custo em relação à receita do G3 foi menor quando comparada aos demais grupos (Tabela 6). A análise dos custos dentro do Cenário COT Valor de Cooperativa mostra que os valores para as embarcações do grupo G3 equivaleram a $28 \%$ da receita, de $35 \%$ para embarcações do G1 e $38 \%$ para

Tabela 4 - Itens de consumo utilizados para a conversão do "Valor Médio Cooperativa" para o "Valor Médio de Mercado", relacionados às operações de pesca dos grupos de embarcações atuantes na pesca do camarão-sete-barbas no litoral norte de São Paulo no ano 2009. A direção das setas, para cima e para baixo, indica a porcentagem da variação do valor cooperativa acima ou abaixo do valor de mercado, respectivamente.

\begin{tabular}{crrrr}
\hline \hline & Diesel & Óleo Lub. & Gelo & Sulfito \\
\hline Cooperativa & $\mathrm{R} \$ 2,01$ & $\mathrm{R} \$ 7,67$ & $\mathrm{R} \$ 3,50$ & $\mathrm{R} \$ 5,50$ \\
Mercado & $\mathrm{R} \$ 2,03$ & $\mathrm{R} \$ 6,73$ & $\mathrm{R} \$ 2,90$ & $\mathrm{R} \$ 4,79$ \\
$\%$ & $1,0 \downarrow$ & $12,3 \uparrow$ & $17,0 \uparrow$ & $12,8 \uparrow$ \\
\hline \hline
\end{tabular}

as do G2. Para o cenário de COT Valor de Mercado os valores encontrados foram $34 \%$ para embarcações do G1, 37\% para as do G2 e $28 \%$ para as embarcações do G3. Assim, a diferença entre o rendimento do cenário COT Valor de Cooperativa e o rendimento do cenário COT Valor de Mercado foi pequena para todas as embarcações em todos os grupos, não atingindo a $2 \%$ em 2009 (Tabela 7).

\section{DISCUSSÃO}

Apesar da análise econômica ser imprescindível para avaliar a situação das pescarias (Abdallah \& Castello, 2003; Ribemboim, 2010), no Brasil, são poucos os estudos sobre manejo de estoques pesqueiros que tem levado em consideração a caracterização socioeconômica e organizacional da atividade sobre a espécie alvo, apesar da sua importância e necessidade, sendo este o caso do camarão sete-barbas (Xiphopenaeus kroyeri). O presente estudo traz, pela primeira vez, resultados sobre os Custos operacionais de captura da frota camaroeira do litoral norte do Estado de São Paulo, com vistas a contribuir para a adequação de políticas públicas voltadas ao ordenamento pesqueiro da espécie.

Em relação aos aspectos econômicos e operacionais da pescaria do camarão-sete-barbas, constatou-se que o óleo combustível representa o 
Tabela 5 - Captura total média, Custo Operacional Total médio, Receita Bruta media, Rendimento médio por quilograma de camarãosete-barbas e de espécies diversas por grupo de embarcação atuante na pesca do camarão-sete-barbas no litoral norte de São Paulo, associadas a COOPERPESCASS no ano 2009.

\begin{tabular}{lrrr}
\hline \hline & G1 & G2 & \multicolumn{1}{c}{ G3 } \\
\hline Captura Total Média (kg) & 13485 & 6021 & 13404 \\
Camarão-sete-barbas & 10657 & 4494 & 11152 \\
Espécies diversas & 2828 & 8138 & 2252 \\
Receita Bruta média Total & $\mathrm{R} \$ 74.640,54$ & $\mathrm{R} \$ 32.600,37$ & $\mathrm{R} \$ 56.134,70$ \\
Camarão-sete-barbas & $\mathrm{R} \$ 32.570,66$ & $\mathrm{R} \$ 14.342,11$ & $\mathrm{R} \$ 34.199,23$ \\
Espécies diversas & $\mathrm{R} \$ 42.069,88$ & $\mathrm{R} \$ 18.258,26$ & $\mathrm{R} \$ 21.935,47$ \\
COT médio & $\mathrm{R} \$ 25.836,08$ & $\mathrm{R} \$ 12.345,70$ & $\mathrm{R} \$ 15.939,48$ \\
Rendimento médio & $\mathrm{R} \$ 48.804,46$ & $\mathrm{R} \$ 20.254,67$ & $\mathrm{R} \$ 40.195,22$ \\
\hline \hline
\end{tabular}

item de maior custo para todos os diferentes grupos de embarcações atuantes no litoral norte do Estado de São Paulo nos dois cenários. Autores como Finco et al. (2003) que estudaram a viabilidade econômica do cultivo de camarão em gaiolas e cercados como alternativa de renda à pesca artesanal, Espírito Santo (2012), que estudou a produtividade e rentabilidade da frota artesanal que captura serra (Scomberomorus brasiliensis) e Benincá (2013), que analisou as pescarias industriais de arrasto em Santa Catarina, chegaram a esta mesma constatação. Por ser o diesel um componente substancial no custo total das pescarias (Sumaila et al., 2008), na realidade brasileira e mundial, há a política pública de subvenção ao óleo diesel. No Brasil a utilização deste recurso é mais freqüente pela frota industrial do que pela frota artesanal e em consulta às colônias de pesca do litoral norte de São Paulo, constatou-se a existência de poucos armadores de pesca que usufruem deste subsídio e os problemas citados para a baixa adesão ao mesmo vão desde a burocracia existente, o pequeno número de postos de combustíveis cadastrados até dificuldades do pescador para o preenchimento das guias. A utilização destas estratégias governamentais não é vista com bons olhos pelos pesquisadores (Abdallah \& Sumaila, 2007; Castello, 2007), sendo considerada necessária, por alguns, sua imediata remoção.

As maiores embarcações (G1), com motores mais potentes, apresentam maior consumo de com- bustível e, em conseqüência, este é o item que mais pesa em seu custo operacional. Já o grupo G3, apesar de apresentar menor motorização, apresenta o maior número de dias de pesca e, desta forma ocupa o segundo lugar quanto ao consumo de diesel dentre os três grupos de embarcações analisados (Azevedo et al., 2014). De acordo com estes autores, as embarcações do $\mathrm{G} 1(\mathrm{~N}=86)$ tiveram 6305 dias de pesca, $\mathrm{G} 2$ $(\mathrm{N}=72) 6537$ dias e o $\mathrm{G} 3(\mathrm{~N}=82)$ com 8657 dias de pesca entre 2008 e 2010.

As embarcações menores (dos grupos G2 e G3) apresentam maiores gastos de rancho que as maiores (do grupo G1), embora estas últimas, em função de seu tamanho, comportem um maior número de tripulantes, e este resultado também está associado ao maior número de viagens realizadas pelas pequenas embarcações (Azevedo, 2013). Tais resultados estão de acordo com os obtidos por Cardoso et al. (2004), que investigaram os aspectos econômicos e sociais da frota pesqueira de Manaus (AM).

Embarcações do grupo G1, por serem maiores em relação ao $A B$, apresentam maior capacidade de estocagem de gelo, óleo lubrificante e sulfito, elementos que representaram a segunda maior fonte de custos para este grupo. Também por suas dimensões, as embarcações do G1 apresentam os maiores gastos com materiais para pescaria, óleo lubrificante e sulfito. Já no caso da manutenção da embarcação, os maiores gastos foram das menores embarcações (G3) e isto

Tabela 6 - Custo Operacional Total médio, Receita Bruta média e Rendimento por embarcação, dos grupos G1, G2 e G3, de embarcações atuantes na pesca do camarão-sete-barbas no litoral norte de São Paulo, em ambos cenários, no ano de 2009.

\begin{tabular}{lccc}
\hline \hline Valor de Cooperativa & G1 & G2 & G3 \\
\hline COT médio & $\mathrm{R} \$ 25.836,08$ & $\mathrm{R} \$ 12.345,70$ & $\mathrm{R} \$ 15.939,48$ \\
Receita Bruta Média & $\mathrm{R} \$ 74.640,54$ & $\mathrm{R} \$ 32.600,37$ & $\mathrm{R} \$ 56.134,70$ \\
Rendimento & $\mathrm{R} \$ 48.804,46$ & $\mathrm{R} \$ 20.254,67$ & $\mathrm{R} \$ 40.195,22$ \\
\%COTMédio/ReceitaBrutaMédia & 35 & 38 & 28 \\
\hline \multicolumn{4}{c}{} \\
\hline Valor de Mercado & $\mathbf{G 1}$ & $\mathbf{G 2}$ & $\mathbf{G 3}$ \\
\hline COT médio & $\mathrm{R} \$ 25.437,45$ & $\mathrm{R} \$ 12.130,32$ & $\mathrm{R} \$ 15.767,97$ \\
Receita Bruta Média & $\mathrm{R} \$ 74.640,54$ & $\mathrm{R} \$ 32.600,37$ & $\mathrm{R} \$ 56.134,70$ \\
Rendimento & $\mathrm{R} \$ 49.203,09$ & $\mathrm{R} \$ 20.470,05$ & $\mathrm{R} \$ 40.366,73$ \\
\%COTMédio/ReceitaBrutaMédia & 34 & 37 & 28 \\
\hline \hline
\end{tabular}


Tabela 7 - Comparação entre o rendimento do Valor de Cooperativa e o rendimento do Valor de Mercado.

\begin{tabular}{|c|c|c|c|}
\hline & G1 & G2 & G3 \\
\hline Rendimento Médio Valor de Cooperativa & $\mathrm{R} \$ 48.804,46$ & $\mathrm{R} \$ 20.254,67$ & $\mathrm{R} \$ 40.195,22$ \\
\hline Rendimento Médio Valor de Mercado & $R \$ 49.203,09$ & $\mathrm{R} \$ 20.470,05$ & $\mathrm{R} \$ 40.366,73$ \\
\hline Diferença & 398,63 & 215,38 & 171,51 \\
\hline Diferença \% & $-0,80 \%$ & $-1,10 \%$ & $-0,40 \%$ \\
\hline
\end{tabular}

pode estar relacionado ao maior número de viagens de pesca realizadas por esse grupo (Azevedo, 2013).

Comparando-se os custos dos itens mencionados, entre dois cenários, Valor de Cooperativa e Valor de Mercado, constata-se que o óleo combustível (diesel) foi o item que apresentou a menor diferença entre eles. Já, para o gelo a diferença de custos entre os dois cenários foi marcante, em decorrência da inexistência de fábricas de gelo no município de São Sebastião, onde se encontra a COOPERPESCASS, sendo este produto proveniente da cidade de Ubatuba $(78 \mathrm{~km}$ distante), e o valor do frete repassado ao cooperado.

A quase igualdade dos rendimentos líquidos para os grupos, entre os dois cenários, é devido ao fato de que nem todos os itens necessários à atividade pesqueira apresentam preço diferenciado, como no caso daqueles comprados diretamente na cooperativa, sendo então adquiridos a preço do mercado local.

Apesar do total das capturas do camarão e de "espécies diversas" (em cuja categoria entra peixes, crustáceos e moluscos) serem semelhantes entre as embarcações maiores (G1) e menores (G3), a Receita Bruta gerada por elas foi distinta: a receita do $\mathrm{G} 1 \mathrm{com}$ "espécies diversas" foi quase o dobro da obtida pelo G3. Isto deve estar relacionado às diferenças nos tipos de espécies e/ou no tamanho dos exemplares capturados. As embarcações com maior motorização, como as do G1, apresentam maior velocidade de arrasto e, conseqüentemente, maior abertura da rede, variáveis estas relacionadas à área varrida (Weinberg \& Kotwicki, 2008), minimizando o escape de organismos de maior porte ou com maior mobilidade, fato que leva ao maior aproveitamento dos mesmos. Os rendimentos obtidos na venda das capturas pelas menores embarcações (G3) foram próximos aos das maiores e, neste caso, tem-se que a explicação pode ser o fato das embarcações do G3 executarem mais dias de pesca (Azevedo, 2013), gerando um volume de captura semelhante ao do G1.

Tratando das receitas obtidas com a venda das capturas (camarões e "espécies diversas"), observa-se que os ganhos das embarcações do G1 foram superiores aos das embarcações dos demais grupos, principalmente com as vendas das capturas de "espécies diversas". O COT do grupo G3 foi inferior ao do $\mathrm{G} 1$, com isso constata-se que, a rentabilidade das embarcações menores foi próximo ao das maiores. Isto se deve à menor participação percentual do custo para pescar das embarcações do G3 quando comparado às embarcações dos outros dois grupos: o custo de pescar das embarcações do G3 foi de $28 \%$ da receita, enquanto que as embarcações dos G1 e G2 foram 34\% e 37\%, respectivamente.

Diante do exposto e sob o ponto de vista econômico, a pequena diferença encontrada entre o rendimento obtido pelo cooperado em relação ao não cooperado, que foi de $2 \%$ ao ano, para todos os grupos de embarcações, não evidencia vantagens econômicas diretas que estimulem adesão ao cooperativismo. Apesar de aparentemente não haver benefícios financeiros em se associar à cooperativa, algumas hipóteses podem ser levantadas sobre as vantagens em fazê-lo, com base na teoria da sociologia econômica que analisa a criação de laços entre os atores.

Os laços fortes podem ocorrer nas relações do pescador com cooperativas e também com intermediários, e são caracterizados pela dependência de um pelo outro e pela exclusividade na comercialização.

Cooperativas de pesca são associações de pessoas cujos objetivos são a compra comum de bens e serviços necessários à atividade profissional e à venda, em comum, da produção dos cooperados. Tais condições visam diminuir os custos operacionais e eliminar os intermediários (Pinho, 1984). Do ponto de vista econômico, a cooperativa atua como uma central de negócios, cuja eficiência depende diretamente da sua capacidade operacional (Maldonado \& Dos Santos, 2006). Quanto ao retorno monetário da venda de seu produto, o pescador, quando cooperado, adquire maior segurança para manter-se na atividade, embora não tenha muita flexibilidade quanto aos valores ganhos na venda de seu produto. No entanto, eles podem se preocupar exclusivamente com a pesca, visto que em terra existe uma logística apropriada para o armazenamento, conservação e venda do pescado. Marrul Filho (2001) salienta que o pescador, em função de executar sua atividade praticamente no ambiente marinho, não se considera um comerciante, e sim um produtor.

O ingresso do pescador na COOPERPESCASS é feito através da compra de uma quota-parte no valor de um salário mínimo no valor vigente, que pode ser pago no ato ou parcelado, não existindo mensalidade. Em caso de desistência do cooperado, o reembolso é efetuado na mesma quantia e da forma que foi acertado anteriormente. O cooperado entrega seu 
produto à cooperativa, que passa a ser a responsável pelo mesmo e o vende tanto na Companhia de Entrepostos e Armazéns Gerais do Estado de São Paulo, CEAGESP, quanto na sua sede, ao preço do dia, repassando quinzenalmente ao pescador $90 \%$ do valor total obtido. Os $10 \%$ restantes são cobrados pela cooperativa como taxas administrativas. Por via contratual, o cooperado só pode vender seu pescado para a cooperativa (direito de exclusividade para a venda) $\mathrm{e}$, ainda existem despesas relativas ao transporte das mercadorias para revenda no CEAGESP, que são descontadas da quantia a ser repassada ao produtor.

A formação de cooperativas é uma das formas de se combater a intermediação desempenhada por terceiros (Charles, 2001; Marrul Filho, 2003), visto que existem situações onde esta relação se dá de forma abusiva.

Estes intermediários podem ser pessoas da comunidade ou ex-pescadores, que se especializaram na comercialização (Marrul Filho, 2003) através da criação de uma parceria na qual o pescador passa a vender seu pescado exclusivamente a esta pessoa. Em situações, em que o pescador está com dificuldades para realizar a manutenção do barco, ou comprar os insumos necessários para realizar a pescaria, o intermediário pode auxiliá-lo. Dependendo da forma como se dá esta relação, do número de pescadores e intermediários, pode vir a ocorrer uma estrutura de mercado denominada oligopsônio, caracterizada por um grande número de ofertantes e poucos demandantes, ou, seja, muitos pescadores ofertando produtos para poucos compradores. O pescador terá pouco poder de barganha junto ao intermediário quanto ao preço da mercadoria, o que pode ser prejudicial para o pescador (Charles, 2001; Ribemboim, 2010).

Os pescadores que não são cooperados e que não estão ligados a intermediários, têm a possibilidade de ganharem mais com a venda direta ao turista e/ ou morador da localidade através da construção de diversos laços fracos com estes, no entanto não possuem os benefícios ou garantias proporcionadas pelo regime de laços fortes. Para colocarem sua mercadoria diretamente no mercado encontram várias dificuldades, como a falta de infraestrutura em termos de acondicionamento, conservação e transporte. Assim, em função da perecibilidade do produto, tendem a vendê-lo a qualquer preço, em um curto período após a captura (Pinho, 1984).

Como mostrado anteriormente, os custos operacionais totais se mostraram semelhantes, em todos os grupos, nos dois cenários (Valor de Cooperativa e Valor de Mercado). No entanto, observa-se que os tipos de laços existentes podem vir a afetar tais custos. Acredita-se que o laço forte com o intermediário não venha a exercer influência na redução dos custos, situação que se assemelha ao cenário de valor de mercado. Por outro lado, apresenta a segurança descrita anteriormente, ou seja, podem assegurar a atuação dos pescadores apenas na atividade pesqueira, estes não se preocupando com outras atividades inerentes à cadeia do pescado. Já no caso do laço forte com a cooperativa, além da citada segurança, existe a possibilidade de redução dos custos operacionais, desde que a cooperativa funcione de forma adequada, conseguindo um maior abatimento com a compra de grandes volumes de insumos e reduzindo o custo a ser repassado ao pescador. No caso da COOPERPESCASS, o pouco investimento para ingresso e a possibilidade de se desligar a qualquer instante são fatores que contam a favor do cooperativismo.

\section{CONCLUSÕES}

Este estudo é o primeiro que faz uma analise econômica de alguns aspectos da pesca do camarão-sete-barbas, no litoral norte de São Paulo.

Dentre os itens de consumo, o óleo diesel consistiu na maior fonte de despesas dentro do custo total da operação. De um modo geral, o custo operacional total variou de acordo com o grupo (porte da embarcação), sendo que as maiores, com motores mais potentes apresentam os maiores gastos para pescar. No entanto, o rendimento médio anual não foi tão distinto entre os grupos das embarcações maiores e o das menores. Em função disso, em um cenário de diminuição das capturas, as embarcações que apresentam o maior COT serão as primeiras a sentir os efeitos do baixo retorno monetário com a venda do pescado. Já as embarcações que apresentam menor participação percentual do custo para pescar, como as do G3, tendem a não sentirem tanto os efeitos em épocas de baixa captura. A relação entre o rendimento e COT pode influenciar na permanência das embarcações na atividade pesqueira e, por conseqüência, na geração e manutenção de empregos diretos e indiretos.

Em se tratando de ações que visem à gestão desta pescaria, acreditamos que as diferenças encontradas nos custos e receitas dos diferentes grupos de embarcações que operam naquela região, para ambos os cenários, possam contribuir para a tomada de decisões sobre seu papel efetivo. Neste caso, devem ser considerados o número de embarcações, as capturas e a relação rendimento/COT.

O consumo de outros itens relativos ao COT e que são necessários à pescaria, como o sulfito, rancho, óleo lubrificante e gelo variou entre os grupos e apresentam diferentes escalas de importância entre eles. A chegada de uma fábrica de gelo no município de São 
Sebastião, onde se encontra a COOPERPESCASS, contribuiria para a redução do COT.

Com a criação de uma cooperativa de pesca, espera-se que ocorra a organização e divisão de tarefas no sentido de aumentar a eficiência do trabaIho e os rendimentos dos cooperados. No entanto, este estudo mostrou a inexistência de vantagens econômicas diretas em relação ao cooperativismo, apesar de salientar alguns benefícios deste sistema de trabalho, principalmente, quanto à segurança que o cooperado tem para se dedicar exclusivamente à atividade pesqueira e para realizar a comercialização de seu produto.

Os resultados mostram que a opção de se tornar cooperado ou não depende principalmente da infraestrutura que o pescador dispõe (física, pessoal ou familiar) para comercializar sua mercadoria indiretamente e da existência ou não de um laço forte com um intermediário. Possivelmente uma cooperativa organizada e funcional, com boa infraestrutura e maior fornecimento de produtos a custos reduzidos, venha a atrair um maior número de interessados.

Uma forma de se compreender as interações entre os diferentes atores presentes na cadeia produtiva que envolve esta pescaria se dá através da análise dos laços fortes e fracos existentes.

\section{AGRADECIMENTOS}

Os autores agradecem ao apoio oferecido pela Cooperativa de Pesca de São Sebastião COOPERPESCASS, de São Sebastião-SP, no desenvolvimento deste trabalho.

\section{REFERÊNCIAS BIBLIOGRÁFICAS}

Abdallah, P. R. \& Castello, J. P., 2003. O momento de repensar a economia pesqueira no Brasil. Disponível em: http://www.comciencia. $\mathrm{br} /$ reportagens/litoral/lit13.shtml, acesso em 30/10/2012.

Abdallah, P. R. \& Sumaila, U. R., 2007. An historical account of Brazilian public policy on fisheries subsidies. Mar. Pol. 31: 444-450

Anderson, L. G. \& Seijo, J. C., 2010. Bioeconomics of fisheries management. Blackwell Publishing. $305 \mathrm{p}$.

ANP, 2013. Agência Nacional de Petróleo. Disponível em: http://www.anp.gov.br/?pg=55347. Acesso em junho de 2013.

Azevedo, V. G., Ávila-da-Silva, A. O. \& RossiWongtschowski, C. L. D. B., 2014. Estudo da frota direcionada à pesca do camarão-sete-barbas, no litoral norte do Estado de São Paulo. Bol. Inst. Pesca 40(2): 179-194

Azevedo, V. G., 2013. Avaliação da Sustentabilidade da Pesca Direcionada ao Camarão-sete-barbas, Xiphopenaeus kroyeri (Heller, 1862), no Litoral Norte do Estado de São Paulo. Tese de doutorado. Instituto Oceanográfico da Universidade de São Paulo. 118 p.

Benincá, E. M., 2013. As pescarias industriais de arrasto-duplo em Santa Catarina - Brasil: dinâmica versus permissionamento. Dissertação de mestrado. Universidade do Vale do Itajaí. 109 p. Berkes, F.; Mahon, R.; McConney, P.; Pollnac, R. \& Pomeroy, R., 2001. Managing small-scale fisheries: alternative directions and methods. IDRC Books, Ottawa, Canada. ISBN: 0-88936-943-7. 304p.

Cardoso, R. S., Batista, V. S., Júnior, C. H. F. \& Martins, W. R., 2004. Aspectos econômicos e operacionais das viagens da frota pesqueira de Manaus, Amazônia Central. Acta Amaz. 34(2): 301-307

Castello, J. P., 2007. Gestão sustentável dos recursos pesqueiros, isto é realmente possível? Pan-Am. J. Aq. Sci. 2(1): 47-52

Charles, A. T., 2001. Sustainable fishery systems. Fish and Aquatic Resources Series N5. Blackwell Science. $370 \mathrm{p}$.

Cristiano Gil Dapper, C. G., 2009. A pesca extrativa marinha em Maceió/AL, sua cadeia produtiva e aspectos institucionais: fragilidades para uma pesca sustentável. Dissertação de Mestrado. Universidade Federal de Alagoas. $134 \mathrm{p}$.

Dupont, D. \& Gordon, D. V., 2007. Shadow prices for fishing quota: fishing with econometrics. In: Bjordal, T., Gordon, D. V., Arnason, R. \& Sumaila, R. (Eds.) Advances in fisheries economics. Festschrift in Honour of Professor Gordon R. Munro. Blackwell Publishing. 304 p.

Espírito Santo, R. V., 2012. Produtividade e rentabilidade da frota artesanal que captura serra (Scomberomorus brasiliensis, Collette, Russo \& Zavalla-Carmin, 1978), na costa norte do Brasil. 2012. Tese (Doutorado em Ecologia Aquática e Pesca) - Universidade Federal do Pará. 112 p.

Finco, M. V. A., Abdallah, P. R. \& Wasieleshy JR, W. F. B., 2003.Viabilidade econômica do cultivo de camarão em gaiolas e cercados como alternativa de renda à pesca artesanal. Estudos \& Debates 10(1): 89-101.

Furlan, E. F., 2011. Valoração da qualidade do camarão sete-barbas (Xiphopenaeus kroyeri) desembarcado no litoral de São Paulo, Brasil. Bol. Inst. Pesca 37(3): 317-326

Graça Lopes, R., Santos, E. P., Severino-Rodrigues, E., Braga, F. M. S. \& Puzzi, A., 2007. Aportes ao 
conhecimento da biologia e da pesca do camarãosete-barbas (Xiphopenaeus kroyeri Heller, 1862) no litoral do estado de São Paulo, Brasil. Bol. Inst. Pesca 33(1): 63-84

Granovetter, M., 1973.The strength of weak ties. Am. J. Sociol. 78(6): 1360-1380.

Granovetter, M., 2005. The impact of social structure on economic outcomes. J. Econ. Perspec. 19(1): 33-50.

Hannesson, R., 2002. The economics of fisheries. In: Hart, P. J. B \& Reynolds, J. D. (Eds.). Handbook of fish biology and fisheries. Volume 2. Blackwell Publishing. 410p.

IBAMA, 2008. Instrução Normativa IBAMA N¹89, de 23 de setembro de 2008.

Instituto de Pesca, 2012. Estatística Pesqueira. Disponível em: http://www.pesca.sp.gov.br/ estatistica/index.php. Acesso em 13/08/2012.

Kalikoski, D.C. \& Vasconcellos, M., 2012.Case study of the technical, socio-economic and environmental conditions of small-scale fisheries in the estuary of Patos Lagoon, Brazil: a methodology for assessment. FAO Fisheries and Aquaculture Circular. No. 1075. Rome, FAO. 2012. 190 pp.

Lopes, F. D. \& Baldi, M., 2005. Laços sociais e formação de arranjos organizacionais cooperativos - Proposição de um modelo de análise. RAC 9(2): 81-101.

Maldonado, F. \& Dos Santos, A. C., 2006. Cooperativas de pescadores artesanais: uma análise sob a perspectiva teórica. Organizações Rurais \& Agroindustriais 8(3): 323-333

Martin, N. B., Serra, R., Antunes, J. F. G., Oliveira, M. D. M. \& Okawa, H., 1994. CUSTOS: sistema de custo de produção agrícola. Inform. Econ. 24(9): 97-122.

Marrul filho, S., 2003. Crise e sustentabilidade no uso dos recursos pesqueiros. Brasília: IBAMA. $147 \mathrm{p}$.

Matsunaga, M., Bemelmans, P. F., Toledo, P. E. N., Dulley, R. D., Okawa, H. \& Pedroso, I. A., 1976. Metodologia de custo de produção utilizada pelo IEA. Agricultura em São Paulo, 23(1): 123-139.
Mendes, R. (2005). Guidebook on melanosis inhibitors and processing technology of crustaceans. Disponível em: http://www.inrb.pt/fotos/editor2/ guidebook.pdf. Acesso em 02/11/2012

Meneses, A. C. S. \& Ogawa, 1977. Uso do bissulfito de sódio na prevenção da "mancha-preta" em camarões, durante a estocagem em gelo, e estimação do dióxido de enxofre residual. Arq. Ciên. Mar 17 (2): 89-93.

Pinho, D. B., 1984. Cooperativas de pesca: noções fundamentais. 3. ed. São Paulo: CNPq. v. 4, cap. 1, p. 125-134. (Manual do cooperativismo - Tipologia cooperativista).

Ribemboim, J., 2010. Economia da pesca sustentável no Brasil. Editora Bagaço, Recife. 261 p.

SEMA, 2005. Zoneamento Ecológico-Econômico Litoral Norte São Paulo / Secretaria de Estado do Meio Ambiente. Coordenadoria de Planejamento Ambiental Estratégico e Educação Ambiental. São Paulo: SMA/CPLEA. $55 \mathrm{p}$.

Souza, K. M., Casarini, L. M., Henriques, M. B., Arfelli, C. A. \& Graça-Lopes, R., 2009. Viabilidade econômica da pesca do Camarão-Sete-Barbas com embarcação de pequeno porte na Praia do Perequê, Guarujá, Estado de São Paulo. Inform. Econ. 39(4): 30-37.

Sumaila, U. R., Teh, L., Watson, R., Tyedmers, P. \& Pauly, D., 2008. Fuel price increase, subsidies, overcapacity and resource sustainability. ICES J. Mar. Sci. 65: 832-840.

Weinberg, K. \& Kotwicki, S., 2008. Factors influencing net width and sea floor contact of a survey bottom trawl. Fish. Res. (93): 265-279. 